\title{
Response to aerosol salbutamol, SCH 1000, and placebo in cystic fibrosis
}

\author{
MEYER KATTAN, ANTHONY MANSELL, HENRY LEVISON, MARY COREY, AND \\ INESE R B KRASTINS
}

From the Department of Paediatrics, and the Research Institute, Hospital for Sick Children, Toronto, Ontario, Canada

ABSTRACT The responses of 20 patients with cystic fibrosis to a B2 agonist, salbutamol, to an anticholinergic agent, $\mathrm{SCH} 1000$, and to a placebo containing difluorodichloroethane and soya lecithin delivered by metered aerosol were compared. Flow rates decreased significantly after placebo $(p<0.05) . F E V_{1}$ increased significantly after salbutamol $(p<0.05)$, but the degree of these changes was small. There was a small but significant increase in FVC but no change in flow rates after $\mathrm{SCH}$ 1000. Specific conductance increased significantly $(\mathrm{p}<0.01)$ after both salbutamol and SCH 1000. Thoracic gas volume remained unchanged with both drugs and placebo. Four of 20 patients had a clinically significant increase in flow rates with SCH 1000 and three with salbutamol. The consistent increases in sGaw coupled with minimal changes in flow rates, suggest that the physiological effects of both agents is to increase the compressibility of the airway. The results after placebo demonstrate the increased airway reactivity to irritants in cystic fibrosis. In view of this, attention should be paid to the possible irritant effects of inhaled medications.

Bronchodilators are often part of the treatment regimen for cystic fibrosis. Patients with this disease demonstrate bronchial hyperreactivity ${ }^{1}$ but their response to bronchodilators is unclear. Data on their usefulness have been conflicting predominantly because of the paucity of controlled studies and the different pulmonary function parameters that have been used for evaluation. In one controlled study, Lifshitz and Denning ${ }^{2}$ found that isoprenaline had a beneficial effect in some patients with cystic fibrosis. In uncontrolled studies some patients were found to have decreased expiratory flow rates after inhalation of isoprenaline. ${ }^{34}$

The use of longer acting and more selective bronchodilators than isoprenaline has recently become widespread in asthma, but their use in cystic fibrosis has not been evaluated. Results with atropine in cystic fibrosis show a decrease in the pulmonary function abnormality, but side effects prohibit its clinical use. ${ }^{5}$

A controlled study was undertaken to assess the bronchodilator effects of a selective B2 agonist, salbutamol, and an anticholinergic agent, SCH 1000 (ipratropium bromide) in cystic fibrosis. Salbutamol

Address for reprint requests: Meyer Kattan, The Mount Sinai Medical Center, One Gustave L Levy Place, New York, NY 10029, USA. has minimal effects on the cardiovascular system and a duration of action of four to six hours. ${ }^{6} \mathrm{SCH} 1000$ is an anticholinergic agent with minimal effects on bronchial secretions or on the cardiovascular system. ${ }^{7}$ It has been used in patients with chronic bronchitis and its bronchodilator effect is better than or comparable to that of a sympathomimetic. ${ }^{89}$ It has also been used as a bronchodilator in asthmatics. $^{10}$

\section{Methods}

Twenty patients with cystic fibrosis (11 males and nine females) were studied. Informed consent to participate in the study was obtained from all subjects (and their parents in the case of minors). They were selected at random from the clinic population and represented a wide variation in clinical severity. They were all experienced in performing the pulmonary function tests in our laboratory so that neither a large intra-patient variability nor a learning effect was expected. The mean age and SD was $14 \cdot 0 \pm 3 \cdot 71$ (range 9 to 22 years). Ten patients had history of wheezing, one had hay fever, and one had a family history of asthma. Fourteen patients had positive skin tests to one or more allergens. 
FVC, the $\mathrm{FEV}_{1}$, and the $\mathrm{FEF}_{25.75 \%}$ were obtained using a Collins nine litre water-filled spirometer. The thoracic gas volume (TGV) at functional residual capacity and airways resistance were measured using a variable pressure body plethysmograph by the techniques described by Dubois et al. ${ }^{11}$ Specific airway conductance was determined from the reciprocal of airway resistance and the simultaneously determined thoracic gas volume. Peak expiratory flow rate was obtained with a Wright's peak flow meter.

The patients were studied in a single-blind manner on two or three separate days. The order of administration of the SCH 1000 and salbutamol was random. If two studies were done on the same day, the first medication was a placebo. In those patients, the SCH 1000 or salbutamol was given after the baseline was re-established or a minimum of four hours later, whichever time was greater. Bronchodilators were omitted for at least eight hours before each study. After measurements of FVC, FEV 1 , $\mathrm{FEF}_{25.75 \%}$, sGaw, and PFR, the patients inhaled either two puffs of placebo, $40 \mu \mathrm{g}$ (two puffs) of SCH 1000 , or $200 \mu \mathrm{g}$ (two puffs) of salbutamol. These doses were delivered by a metered-dose inhaler which contained difluorodichloroethane as the main inert propellant, and soya lecithin as the surfactant. After inhalation, the FVC, $\mathrm{FEV}_{1}$, and $\mathrm{FEF}_{25-75 \%}$ were repeated at 15 and 30 minutes. The $\mathrm{FEF}_{25-75 \%}$ post-bronchodilator was calculated using the prebronchodilator FVC so that comparisons were made at the same lung volume. The sGaw and PFR were repeated only at 30 minutes.

The doses chosen for bronchodilators have been previously reported to be effective in patients with asthma ${ }^{12}$ and bronchitis. ${ }^{8}$ The 30 -minute duration of assessment was used because both salbutamol and SCH 1000 achieve their peak effect within this time. ${ }^{6}$

A paired $t$ test was used for analysis of the response to bronchodilators. An unpaired $t$ test was used to assess difference in baseline pulmonary function.

\section{Results}

The mean baseline percent predicted FVC, FEV and $\mathrm{FEF}_{2575 \%}$ are shown in table 1. The range for baseline $\mathrm{FEV}_{1}$ was $32 \%$ to $87 \%$ predicted and for the baseline $\mathrm{FEF}_{25.75 \%}$, it was $15 \%$ to $86 \%$ predicted. The response to bronchodilator was assessed by calculating the percentage change from baseline.

Table 1 shows the results after inhalation of placebo, SCH 1000, and salbutamol for the duration of the study period. Pulmonary function was similar at the beginning of each drug trial. Forced vital capacity increased after both $\mathrm{SCH} 1000$ and
Table 1 Percentage predicted FVC, FEV , and $F E F_{25-75}$, and the difference from baseline after the drug indicated (mean $\pm 1 S E)$

\begin{tabular}{|c|c|c|c|c|}
\hline \multirow{3}{*}{$\begin{array}{l}\text { Time }(\mathrm{min}) \\
\text { Drug } \\
\text { Placebo } \\
\text { SCH } 1000 \\
\text { Salbutamol }\end{array}$} & \multicolumn{4}{|c|}{ FVC $(\%$ predicted $)$} \\
\hline & 0 & 5 & 15 & 30 \\
\hline & $\begin{array}{l}76 \cdot 8 \pm 3 \cdot 8 \\
76 \cdot 2 \pm 3 \cdot 7 \\
77 \cdot 6 \pm 3 \cdot 7\end{array}$ & $\begin{array}{c}-0.6 \pm 1.0 \\
1.0 \pm \cdot 8 \\
1.4 \pm \cdot 6^{*}\end{array}$ & $\begin{array}{r}-1 \cdot 2 \pm 1 \cdot 1 \\
1 \cdot 7 \pm \cdot 8^{*} \\
2 \cdot 2 \pm \cdot 9^{*}\end{array}$ & $\begin{array}{r}-2 \cdot 2 \pm 1 \cdot 4 \\
2 \cdot 0 \pm \cdot 9 * \\
1 \cdot 8 \pm 1 \cdot 0\end{array}$ \\
\hline \multicolumn{5}{|c|}{$F E V_{1}(\%$ predicted $)$} \\
\hline $\begin{array}{l}\text { Time (min) } \\
\text { Drug }\end{array}$ & 0 & 5 & 15 & 30 \\
\hline $\begin{array}{l}\text { Placebo } \\
\text { SCH } 1000 \\
\text { Salbutamol }\end{array}$ & $\begin{array}{l}62 \cdot 4 \pm 3 \cdot 8 \\
61 \cdot 2 \pm 3 \cdot 7 \\
62 \cdot 1 \pm 3 \cdot 9\end{array}$ & $\begin{array}{c}-0.7 \pm \cdot 7 \\
0.0 \pm \cdot 8 \\
-0.5 \pm 1 \cdot 2\end{array}$ & $\begin{array}{c}-2 \cdot 7 \pm 1 \cdot 2^{*} \\
1.4 \pm \cdot 8 \\
2 \cdot 8 \pm \cdot 8 \dagger\end{array}$ & $\begin{array}{l}-3 \cdot 2 \pm 1 \cdot 3^{*} \\
1 \cdot 0 \pm \cdot 9 \\
2 \cdot 1 \pm 1 \cdot 0^{*}\end{array}$ \\
\hline \multicolumn{5}{|c|}{$F E F: 5-75 \%$ ( $\%$ predicted $)$} \\
\hline $\begin{array}{l}\text { Time }(\min ) \\
\text { Drug }\end{array}$ & 0 & 5 & 15 & 30 \\
\hline $\begin{array}{l}\text { Placebo } \\
\text { SCH } 1000 \\
\text { Salbutamol }\end{array}$ & $\begin{array}{l}41 \cdot 0 \pm 4 \cdot 8 \\
38 \cdot 8 \pm 4 \cdot 8 \\
40 \cdot 4 \pm 5 \cdot 1\end{array}$ & $\begin{array}{r}-2.6 \pm 1.5 \\
-1.0 \pm 1.9 \\
2.4 \pm 1.3\end{array}$ & $\begin{array}{r}-4 \cdot 1 \pm 2 \cdot 4 \\
.4 \pm 1 \cdot 3 \\
5 \cdot 8 \pm 1 \cdot 7 \dagger\end{array}$ & $\begin{array}{c}-7 \cdot 6 \pm 3 \cdot 2 * \\
1.8 \pm 1 \cdot 7 \\
2 \cdot 4 \pm 2 \cdot 1\end{array}$ \\
\hline
\end{tabular}

* $\mathrm{p}<0.05$

$+\mathrm{p}<0.01$

salbutamol $(\mathrm{p}<0.05)$. This increase was apparent $\stackrel{\infty}{\circ}$ at five minutes for salbutamol and at 15 minutes for SCH 1000 . These changes in FVC were statistically significant although relatively small.

Fifteen minutes after inhalation of placebo aerosol flow rates decreased $(p<0.05)$. There was a signifi- $\stackrel{\mathbb{Q}}{\Omega}$ cant increase in $\mathrm{FEV}_{1}$ and $\mathrm{FEF}_{25.75 \%}(\mathrm{p}<0.05)$ by $\underset{\vec{\rho}}{\Rightarrow}$ 15 minutes after salbutamol, but the response $\frac{\circ}{3}$ diminished by 30 minutes. There were no significant $\vec{\partial}$ changes in flow rates after inhalation of SCH 1000 .

Based on the response to bronchodilators and bronchoconstrictors in normal individuals usin various parameters of pulmonary function, a change of clinical importance was determined to be $10 \%$ for $\mathrm{FEV}_{1}$ and $25 \%$ for $\mathrm{FEF}_{25 \cdot 75 \%}{ }^{1314}$ Four of the 20 patients $(20 \%)$ had a reduction of this degree in either the $\mathrm{FEV}_{1}$ or the $\mathrm{FEF}_{25} 75 \%$ after the placebo. Two patients had these reductions in flow aftero SCH 1000 and one patient after salbutamol. Four of $20(20 \%)$ had these increases after SCH 1000 ando three of $20(15 \%)$ after salbutamol. Only one subject had these increases to both SCH 1000 ando salbutamol.

The effects of the drugs on TGV and PFR areN shown in table 2 . Thoracic gas volume remained ${ }_{O}^{\omega}$ unchanged with all three drugs. Peak expiratory flowincreased significantly with SCH $1000(\mathrm{p}<0.05)$ ? and salbutamol $(\mathrm{p}<0.01)$, but not with placebo.

Specific airway conductance increased with both salbutamol and SCH $1000(\mathrm{p}<0.01)$ but remained unchanged with placebo (figure).

Age, sex, baseline pulmonary function, and presence of skin test hypersensitivity did not correlate with the response to bronchodilators.

Side effects were minimal with both SCH 1000 


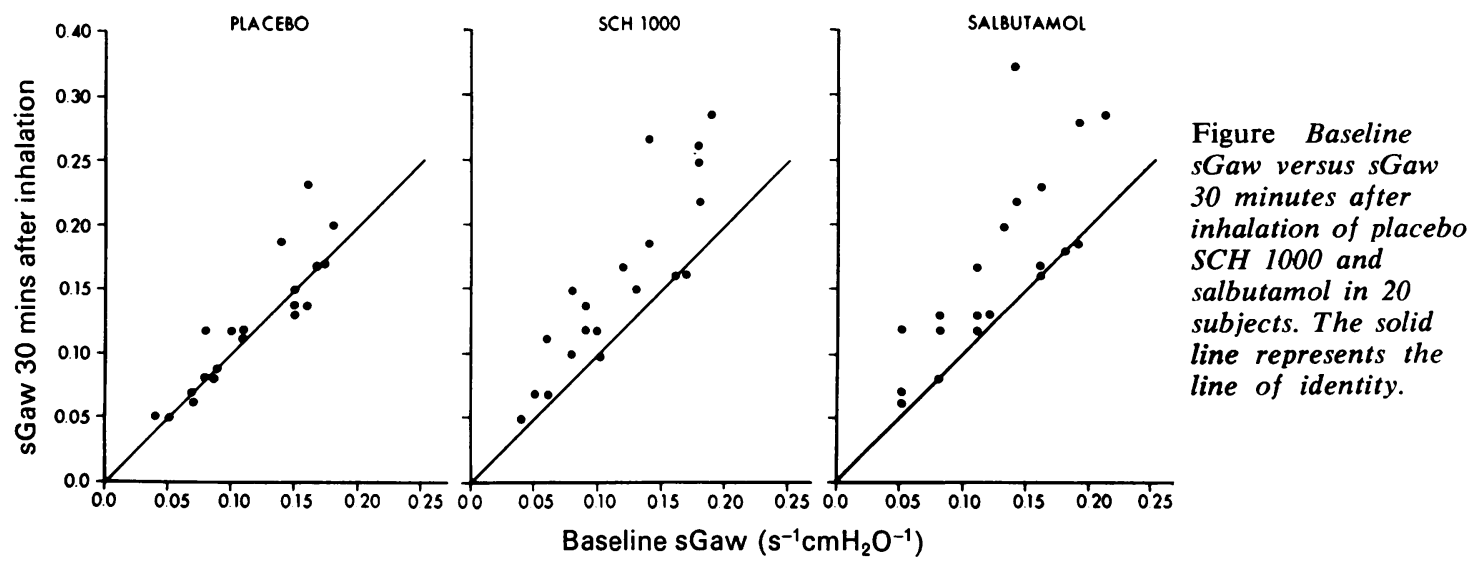

Table 2 Mean $\pm S E$ peak flow rate $(P F R)$ and thoracic gas volume (TGV) for 20 patients before and after drug indicated

\begin{tabular}{llll}
\hline PFR (litre/min) & Placebo & $S C H \quad 1000$ & Salbutamol \\
\hline Baseline & $314 \cdot 1 \pm 18 \cdot 3$ & $300 \cdot 3 \pm 14 \cdot 3$ & $322 \cdot 9 \pm 17 \cdot 8$ \\
30 min & $312 \cdot 7 \pm 18 \cdot 3$ & $319 \cdot 1 \pm 13 \cdot 1$ & $341 \cdot 7 \pm 17 \cdot 3$ \\
& NS & $\mathrm{p}<0 \cdot 05$ & $\mathrm{p}<0 \cdot 001$ \\
TGV (litres) & & & \\
Baseline & $2 \cdot 33 \pm 0 \cdot 15$ & $2 \cdot 39 \pm 0 \cdot 17$ & $2 \cdot 31 \pm 0 \cdot 19$ \\
30 min & $2 \cdot 28 \pm 0 \cdot 17$ & $2 \cdot 28 \pm 0 \cdot 16$ & $2 \cdot 24 \pm 0 \cdot 16$ \\
& NS & NS & NS \\
\hline
\end{tabular}

NS - not significant

and salbutamol. Mean heart rate before salbutamol was 91.2 beats $/ \mathrm{min}$ and this increased to 96.0 beats/min after the inhalation $(p<0.05)$. With $\mathrm{SCH} 1000$ heart rate increased from a pre-treatment rate of $92.0 / \mathrm{min}$ to 93.1 after treatment (not significant). The mean heart rate before and after placebo remained at 92.1 beats per minute. Dryness of the mouth was reported only on specific enquiry in one subject with SCH 1000.

\section{Discussion}

Both salbutamol and SCH 1000 caused significant changes in the patients with cystic fibrosis but the pattern of bronchodilation differed strikingly from that seen in asthmatics. Specific airway conductance increased consistently but forced expiratory flow usually remained unchanged and in several instances actually decreased. This pattern has been observed in normal subjects after bronchodilators. ${ }^{15} 16 \mathrm{De}$ creased flows after bronchodilators have been reported in uncontrolled studies in some patients with cystic fibrosis but not in conjunction with increased conductance. ${ }^{3} 4$

Since sGaw increased consistently and is determined primarily by the diameters of central airways ${ }^{17}$ it is possible that the drugs had selective effects on the central airways. Our patients had varying degrees of peripheral airway obstruction which would favour deposition of the aerosol in central airways. This may partly explain the consistent increase in sGaw but does not explain the decrease in forced expiratory flow observed in some patients. Furthermore, if the precise site of aerosol deposition were critical, those with mild disease should have had an increase in conductance and flow rates whereas those with severe disease only an increase in conductance. This pattern was not observed.

Studies of lung mechanics have explained certain characteristics of pulmonary function tests in patients with cystic fibrosis. Peak expiratory flow rates and maximum voluntary ventilation may be nearly normal in the face of severe airway obstruction and expiratory iso-volume flow-pressure curves show a remarkable preservation of effort dependent flow at high lung volumes. ${ }^{18}$ Further studies have suggested that these findings are the result of compression of gas in ectatic central airways rather than the preservation of normal lung units. ${ }^{19}$

Compressibility of airways is a determinant of maximum expiratory flow. According to theory of flow limitation advanced by Pride et $a l,{ }^{20}$ the reductions in maximum expiratory flow after bronchodilators in some of our patients may be caused by decrease in peripheral airways conductance, decrease in lung recoil, or increase in the critical transmural pressure at which dynamic compression of airways occurs. It is unlikely that the bronchodilators decreased peripheral airways conductance. Isoprenaline in large doses has been shown to reduce lung recoil, ${ }^{15}$ but not in smaller doses. ${ }^{16}$ Atropine given intravenously can also decrease lung recoil. ${ }^{21}$ In our study the inhaled doses of the beta-adenergic and the anticholinergic bronchodilators were small and it is unlikely a dcerease in lung recoil is the explanation for the reduced or unchanged flow rates. 
Bronchodilators increase compliance of airways ${ }^{22}$ and this would increase the tendency for dynamic compression which would reduce maximum expiratory flow. The variability of our results for maximal expiratory flow which increased, decreased, or remained unchanged after the bronchodilators, probably represents the opposing effects of decrease in airway resistance and increase in airway collapsibility.

The significant reduction in flow rates after placebo containing propellant and lubricant has not been reported previously in cystic fibrosis. Difluorodichloroethane and soya lecithin have been shown to decrease specific conductarce and flow rates in some asthmatics but not in normal subjects. ${ }^{23} 24$ This same observation in patients with cystic fibrosis may be related to heightened bronchial reactivity to irritants that has been demonstrated in this disease. ${ }^{25}$ The relative contribution of the propellant and surfactant to the bronchoconstriction is unknown. Depite flow rates being reduced after placebo, sGaw did not change significantly. The explanation for this observation is unclear. It may indicate a negligible effect of irritants on ectatic large airways. The possibility remains that the reduction in flow rates results from the effect of forced expiratory mechanical manoeuvres on ectatic airways. However, if it were solely a mechanical effect, similar changes should have been observed after SCH 1000 and salbutamol.

Bronchodilators in cystic fibrosis must be evaluated from their clinical effect rather than their statistical significance. Statistically, salbutamol causes greater improvement in flow rates than SCH 1000 but the beneficial effect of both is small in terms of clinical improvement in most patients. The percentage changes from baseline were greater with the $\mathrm{FEF}_{25-75 \%}$ than with the $\mathrm{FEV}_{1}$. This points out that large percentage changes are not synonymous with statistical or clinical significance of the test when determining a response to bronchodilators. In addition, using sGaw or PFR as the only parameters for assessment may be misleading because they may simply be reflecting an effect on large ectatic airways.

The small responses observed are comparable to previous studies using isoprenaline in cystic fibrosis. ${ }^{2} 326$ When bronchoconstriction is induced with methacholine in patients with cystic fibrosis the response to salbutamol is slower and less complete than in asthmatics. ${ }^{1}$ Nevertheless, in those patients demonstrating a response, $\mathrm{SCH} 1000$ and salbutamol might be preferable to isoprenaline because of fewer side effects and longer duration of action.

Whether or not anticholinergic agents delivered by a different method would be more useful than a

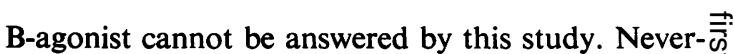
theless, the response to $\mathrm{SCH} 1000$ would suggest thato some patients have increased vagal tone which is in들 agreement with observations using atropine in $\overline{\bar{p}}$ patients with cystic fibrosis. ${ }^{5}$

The treatment regimen in cystic fibrosis includes many drugs. In view of the heightened bronchial ${ }^{\text {s }}$ reactivity that some patients demonstrated to the $\vec{O}$ propellant and surfactant, attention should be paid $\vec{A}$ to the possibility of detrimental effects on the airways $\omega$ from other medications caused by their method of $F$ delivery and their chemical and physical properties.

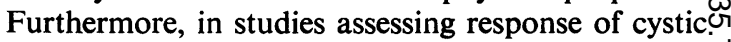
fibrosis patients to inhaled medications, the impor-iv tance of airway irritability to placebo should be assessed.

We would like to thank Dr GH Worsley for hisc advice and assistance and Boehringer Ingelheim for the supply of the SCH 1000 and placebo aerosols.

\section{References}

1 Mitchell I, Corey M, Woenne R, Krastins I, Levison $H$. Bronchial hyperreactivity in cystic fibrosis and asthma. J Pediatr 1978; 93:744-8.

2 Lifschitz MI, Denning CR. Assessment of bronchospasm in patients with cystic fibrosis. Am Rev Respir Dis 1969; 99:399-405.

3 Landau LI, Phelan PD. The variable effect of a 3 bronchodilating agent on pulmonary function in cystic fibrosis. J Pediatr 1973; 82:863-8.

4 Zapletal A, Motoyama EK, Gibson LE Bouhuys A. Pulmonary mechanics in asthma ando cystic fibrosis. Pediatrics 1971; 48:64-72.

5 Larsen GL, Barron RJ, Cotton EK, Brooks JG.: A comparative study of inhaled atropine sulfatc and isoproterenol hydrochloride in cystic fibrosis. Am Rev Respir Dis 1979; 119:399-407.

6 Ruffin RE, Fitzgerald JD, Rebuck AS. A comparison of the bronchodilator activity of $\mathrm{SCH}^{\circ}$ 1000 and salbutamol. J Allergy Clin Immunot 1977; 59:136-41.

7 Engelhardt A, Klupp H. The pharmacology and toxicology of a new tropane alkaloid derivative? Postgrad Med J 1975; 51 (suppl 7):82-5.

8 Poppius H, Salorinne Y. Comparative trial of $N$ new anticholinergic bronchodilator, SCH 1000 , and salbutamol in chronic bronchitis. $\mathrm{Br}$ Med 1973; 4:134-6.

9 Petrie GR, Palmer KNV. Comparison of aeroso iprapropium bromide and salbutamol in chronic bronchitis and asthma. $\mathrm{Br}$ Med $J$ 1975; 1:430-2-

10 Storms WW, Guillermo AD, Reed CE. AerosolD SCH 1000. Am Rev Respir Dis 1975; 111:419-22

11 Dubois AB, Botelho SY, Comroe JH. A rapic plethysmographic method for measuring thoraci gas volume. J Clin Invest 1956; 35:322-6.

12 Gross NJ. SCH 1000: a new anticholincrgio 
bronchodilator. Am Rev Respir Dis 1975; 112: 823-8.

13 Lorber DB, Kaltenborn W, Burrows B. Responses to isoproterenol in a general population sample. Am Rev Respir Dis 1978; 118: 855-61.

14 Kattan M, Keens TG, Mellis CM, Levison $H$. The response to exercise in normal and asthmatic children. J Pediatr 1978; 92:718-21.

15 McFadden ER, Newton-Howes J, Pride NB. Acute effects of inhaled isoproterenol on the mechanical characteristics of the lungs in normal man. J Clin Invest 1970; 49:779-90.

16 Bouhuys A, Van de Woestijne P. Mechanical consequences of airway smooth muscle relaxation. J Appl Physiol 1971; 30:670-6.

17 Bouhuys A. Pulmonary response to bronchodilators. Am Rev Respir Dis 1974; 110:119-21.

18 Mellins RB, Levine OR, Ingram RH, Fishman P. Obstructive disease of the airways in cystic fibrosis. Pediatrics 1968; 41:560-73.

19 Landau LI, Taussig LM, Macklem PT, Beaudry PH. Contribution of inhomogeneity of lung units to the maximal expiratory flow-volume curve in children with asthma and cystic fibrosis. Am Rev Respir Dis 1975; 111:725-31.

20 Pride NB, Permutt S, Riley L, BrombergerBarnea B. Determinants of maximal expiratory flow from the lungs. J Appl Physiol 1967; 23: 646-62.

21 Vincent NJ, Knudson R, Leith DE, Macklem PT, Mead J. Factors influencing pulmonary resistance. J Appl Physiol 1970; 29:236-43.

22 Coburn RF, Thornton D, Arts R. Effect of trachealis muscle contraction on tracheal resistance to air flow. J A ppl Physiol 1972; 32:397-403.

23 Brook SM, Mintz S, Weiss E. Changes occurring after freon inhalation. Am Rev Respir Dis 1972; 105:640-3.

24 Sterling GM, Batten JC. Effect of aerosol propellants and surfactants on airway resistance. Thorax 1969; 24:228-31.

25 Mellis CM, Levison $H$. Bronchial reactivity in cystic fibrosis. Pediatrics 1970; 61:446-50.

26 Featherby EA, Weng TR, Levison $H$. The effect of isoproterenol on airway obstruction in cystic fibrosis. Can Med Assoc J 1970; 102:835-8. 